ESPAÇO TEMÁTICO: VIOLÊNCIA, SAÚDE E CLASSES SOCIAIS

\title{
"O lixo vai falar, e numa boa!"”
}

\author{
Rachel Gouveia Passos ${ }^{1}$ \\ https://orcid.org/0000-0003-2267-0200 \\ ${ }^{1}$ Universidade Federal do Rio de Janeiro, Escola de Serviço Social, Departamento de Métodos e Técnicas, Rio de Janeiro, \\ RJ, Brasil
}

\section{"O lixo vai falar, e numa boa!"}

Resumo: O presente artigo tem o intuito de problematizar o sofrimento produzido pela negação da maternidade das mulheres negras, fruto do racismo e das desigualdades existentes em nossa sociedade. Por trás das fatalidades geradas pelo racismo e pela violência estrutural, buscamos sinalizar que existe um projeto que "não autoriza" as mulheres negras a serem mães, apesar da maternidade estar colocada compulsoriamente para o gênero feminino. Desta maneira, em uma sociedade racista, patriarcal, sexista, colonialista e elitista, nem todas podem usufruir do "mito do amor materno", e isso vem sendo colocado através da produção e reprodução do sofrimento, da violência e do racismo em suas mais diversas expressões.

Palavras-chave: Mulheres negras. Racismo. Violência. Sofrimento.

\section{"Trash will speak up, and in a nice way!"}

Abstract: This article intends to discuss the suffering produced by the denial of black women's motherhood, the result of racism and inequalities existing in our society. Behind the fatalities generated by racism and structural violence, we seek to signal that there is a project that "does not authorize" black women to be mothers, despite the fact that motherhood is compulsorily placed for the female gender. Thereby, in a racist, patriarchal, sexist, colonialist and elitist society, not everyone can enjoy the "myth of maternal love" and this has been placed across the production and reproduction of suffering, violence and racism in its most diverse expressions.

Keywords: Black Women. Racism. Violence. Suffering.

Recebido em 16.09.2020. Aprovado em 15.12.2020. Revisado em 25.01.2021. 


\section{Introdução}

Adriana Pires da Silva é mãe de Carlos Eduardo da Silva Souza, de 16 anos, um dos cinco jovens assassinados com mais de 100 tiros disparados pela polícia no dia 25 de novembro de 2015, em Costa Barros. Os rapazes, todos negros e com idades entre 15 e 25 anos, voltavam para casa após comemoração do primeiro emprego de um deles, quando o carro em que viajavam foi metralhado pela polícia. Além do ataque desproporcional, os policiais ainda tentaram incriminar os rapazes e alterar a cena do crime e suprimir provas. Adriana, devastada, já tentou suicídio três vezes desde a morte de seu filho. As mães e pais dos outros rapazes seguem aguardando reparação e punição dos culpados (IRACI; WERNECK, 2016).

Joselita de Souza, mãe do menino Roberto, 16 anos, também morto por policiais militares na Chacina de Costa Barros, teve sua vida tirada pela dor da perda. Segundo familiares, em entrevista ao jornal $O$ Globo, o motivo da morte, ocorrida no dia 07 de julho de 2019, foi tristeza pela falta do filho e de Justiça, diante das evidências do crime. Joselita era cabeleireira e, segundo a família, nunca teve problemas de saúde e sempre foi muito alegre. $\mathrm{O}$ filho Roberto morou com ela até os 10 anos, depois passou a viver com o pai, mas conversava com a mãe todos os dias. Ele havia começado em um emprego e prometido para Joselita que lhe daria um presente com o primeiro salário que recebeu do programa Jovem Aprendiz, no dia de sua morte (BRISO, 2019).

Segundo o Atlas da Violência, publicado em 2019, existe uma juventude perdida, ou seja, vem sendo crescente a morte prematura de jovens (entre 15 e 29 anos) por homicídio. Esse é um fenômeno que está em alargamento no País desde os anos 1980. Só no ano de 2017, 35.783 jovens foram assassinados no Brasil. "Esse número representa uma taxa de 69,9 homicídios para cada 100 mil jovens no país, taxa recorde nos últimos dez anos" (CARVALHO, 2019, p. 1), o que significa que teremos severas implicações mais à frente devido a uma mudança demográfica ocasionada pelo processo de envelhecimento da população, em especial nas famílias negras, pobres e periféricas. Cabe salientar que ainda não temos dados que revelam os homicídios contra crianças, mas só na cidade do Rio de Janeiro, pelo menos seis crianças foram mortas em 2019 (CARVALHO, 2019).

Ao resgatarmos alguns casos e dados acerca da violência que atravessa a juventude negra, objetivamos problematizar o sofrimento produzido pela negação da maternidade das mulheres negras, fruto do racismo e das desigualdades existentes em nossa sociedade. Por trás das fatalidades geradas pelo racismo e pela violência estrutural, podemos sinalizar que existe um projeto que não autoriza as mulheres negras a serem mães, apesar da maternidade estar colocada compulsoriamente para o gênero feminino. Dessa maneira, em uma sociedade racista, patriarcal, sexista, colonialista e elitista, nem todas as mulheres podem usufruir do mito do amor materno, e isso vem sendo colocado através da produção e reprodução do sofrimento, da violência e do racismo em suas mais diversas expressões.

\section{Sofrimento e a racialização da existência}

O sofrimento precisa ser deslocado para uma discussão que não fique restrita ao campo da saúde mental. Para Basaglia (1979, p. 37-38), "o sofrimento humano é algo que não se pode eliminar. Está na vida, está no homem, é uma condição do homem. O problema da vida é a contradição entre o que é a organização social e a dor que se expressa em cada um de nós". É importante compreendermos que a existência humana possui uma dor que é inerente ao ser, logo, faz parte da constituição da humanidade o sofrimento. Segundo Leão, Ianni e Goto (2019, p. 53), é equivocado reduzir o sofrimento psíquico apenas à experiência individual e singular, isolando-a dos referenciais sociossimbólicos, já que, "ao mesmo tempo em que duas pessoas não experimentam o sofrimento de forma absolutamente igual, há também algo comum, algo coletivamente individualizado". Para os autores, o sofrimento pode estar relacionado a, pelo menos, quatro dimensões: individual, social, coletiva e institucional, sendo indissociáveis, multideterminadas e multideterminantes.

Basaglia (1979, p. 38) nos mostra que aquele que tem acesso econômico para expressar seu sofrimento existencial pode se manifestar subjetivamente. Já aquele que "não tem condições econômicas para sobreviver, não pode se expressar de maneira alguma, não conhece o sofrimento existencial, mas somente o sofrimento da sobrevivência, não havendo assim a possibilidade de expressar a contradição e o antagonismo". Para o autor, todos temos o direito de nos manifestarmos como cidadãos, entretanto, será o poder que determinará a forma como iremos nos expressar. 
O silenciamento e aniquilação de determinadas existências compõem as estratégias de um projeto de sociedade que está assentado na distribuição desigual dos poderes e que desumanizou a população negra. Fanon (2008) nos mostra como o colonialismo criou a existência negra e produziu questionamentos acerca de sua humanidade. Assim, tudo o que sempre esteve relacionado ao negro (cultura, tradições, idiomas, estética etc.) foi considerado inferior e menosprezado, ou seja, "o colono [fez] do colonizado uma espécie de quintessência do mal" (FANON, 2015, p. 58), colocando-nos na zona do "não ser". Por consequência, essa inferiorização acontece em um duplo processo: inicialmente no sentido econômico, e, depois, pela interiorização dessa inferioridade (FANON, 2008).

Esse processo de inferiorização se expressa a partir do momento que se tem a padronização do ser negro por meio da racialização da existência. Fanon (1980), ao tratar sobre os antilhanos e africanos, nos mostra como a colonização criou mecanismos que resultaram na padronização do ser negro a partir da racialização dos corpos, comportamentos, tradições, estética etc. Logo, o que se procura ao englobar todos os negros no termo "povo negro" é arrebatar-lhes toda a possibilidade de expressão individual. O que se procura assim é obrigá-los a corresponder à ideia que já se faz deles" (FANON, 1980, p. 21). Ou seja, significa que de certa forma todos os negros são parecidos e ligados, simplesmente por serem negros, levando a uma aniquilação da diversidade dos povos existentes e recriando uma outra identidade e subjetividade.

Para Quijano (2005), com a colonização da América os colonos encontraram muitos povos diferentes, sendo que cada um tinha sua própria história, linguagem, memória, identidade, cultura etc. "Trezentos anos mais tarde todos eles reduziam-se a uma única identidade: índios. Esta nova identidade era racial, colonial e negativa. Assim também sucedeu com os povos trazidos forçadamente da futura África como escravos", o que significou que "no lapso dos trezentos anos, todos eles não eram outra coisa além de negros" (QUIJANO, 2005, p. 127). Nesse sentido, criou-se a existência negra e indígena, tendo por consequência a produção de um determinado sofrimento de sobrevivência que hierarquizou a humanidade.

Portanto, o racismo é contra determinadas formas de existir, por isso precisa retirar o poder econômico, inferiorizar subjetivamente e aniquilar os valores culturais que sustentam esses povos. Nesse caminho, acontece a desumanização dessa existência através do apagamento da dor que compõe a humanidade e a transforma em sofrimento da sobrevivência. A existência negra foi remodelada pela dominação do colonizador que buscou afirmar maciçamente a sua superioridade. Para Quijano (2005), a Europa criou um novo padrão de poder mundial que concentrou sobre sua hegemonia as formas de controle da subjetividade e do sofrimento, o que fez com que definisse a experiência de ser negro, louco, mulher, LGBT.

\section{“Não sou eu uma mulher?”}

O processo de colonização não se deu sem violência (FANON, 2015). De acordo com Bell Hooks (2019), já no início do colonialismo, ao serem colocados a bordo de um navio, mulheres e homens africanos eram marcados com ferro quente. Havia um chicote denominado de "gato de nove caudas" que foi usado para açoitar aqueles que gritassem ou resistissem à tortura. "O estupro era um método comum de tortura usado pelos escravizadores para subjugar negras recalcitrantes. A ameaça de estupro e de outras violências físicas causava terror psíquico nas africanas que haviam sido deslocadas" (BELL HOOKS, 2019, p. 41). Além disso, os escravizadores violentavam as crianças para assistir o sofrimento da mãe e promover ridicularização e desprezo. Para Sueli Carneiro (1995, p. 546), "o estupro colonial da mulher negra pelo homem branco no passado e a miscigenação daí decorrente criaram as bases para a fundação do mito da cordialidade e da democracia brasileira".

As experiências traumáticas de mulheres e homens a bordo de navios negreiros foram apenas as primeiras etapas de um processo de doutrinação que transformaria o ser humano africano livre em escravo. Um aspecto importante no trabalho do escravizador era efetivamente transformar a personalidade africana a bordo dos navios, para que fosse comercializada como um "escravo dócil" nas colônias americanas. O espírito orgulhoso, arrogante e independente das pessoas africanas precisava ser quebrado, para que estivesse em conformidade com o conceito que o colonizador branco tinha de comportamento escravo apropriado. Eram cruciais, no preparo das pessoas africanas para o mercado de escravos, a destruição da dignidade humana, a eliminação de nomes e status, a dispersão de grupos, para não haver uma língua comum, e retirada de 
qualquer sinal evidente de herança africana. Os métodos que os escravizadores usavam para desumanizar mulheres e homens africanos eram diversas torturas e variados castigos. Um escravizado poderia ser severamente espancado por cantar uma música triste. Quando considerava necessário, o escravizador assassinava com crueldade um escravizado para inspirar terror naqueles a que assistiam. Esses métodos de aterrorizar eram bem-sucedidos no propósito de forçar as pessoas africanas a reprimir a consciência de sua liberdade e adotar a identidade de escravizado que lhe era imposta. (BELL HOOKS, 2019, p. 43).

Bell Hooks (2019) considera que para as mulheres africanas era destinada a pior parte dessa violência em massa. Isto ocorria "não somente porque poderiam ser vitimadas pela sexualidade, mas também porque eram mais propensas a trabalhar intimamente com a família branca do que os homens negros" (BELL HOOKS, 2019 , p. 44). A mulher negra teria funções na casa-grande e por isso era crucial que fosse tão aterrorizada para se submeter passivamente aos desejos e vontades do senhor, da senhora e das crianças brancas. "A fim de tornar seu produto vendável, o escravizador precisava garantir que nenhuma criada negra recalcitrante envenenasse a família, matasse crianças, incendiasse a casa ou oferecesse resistência de qualquer outra forma" (BELL HOOKS, 2019, p. 44).

No caso brasileiro, Giacomini (1988) aponta que para compreendermos a composição e a formação do proletariado brasileiro é necessária uma análise das transformações dos negros e negras escravizados/as em trabalhadores livres e, também, da herança deixada pela escravidão para as mulheres negras. Nesse sentido, para a autora é primordial uma reelaboração da história da escravidão brasileira e da compreensão das raízes históricas da situação atual da mulher negra no Brasil. Portanto, a forma como está colocada a existência da mulher negra e do sofrimento a ela destinado na contemporaneidade está vinculada às bases colonialistas, racistas, patriarcais, elitistas e classistas que sustentam a formação social brasileira.

Primeiramente é importante sinalizar que para a mulher negra é negada a sua condição de mulher. Em seu estudo, Giacomini (1988) nos mostra como o colonialismo brasileiro produziu a negação da maternidade para a mulher negra, condição essa que foi tornada essencial e naturalizada como atribuição e condição do feminino. Apesar da maternidade estar vinculada às características consideradas femininas, é necessário destacar que a mulher negra foi coisificada, logo, a sua maternidade foi mercantilizada e negados a ela a escolha e o direito de ser mãe. "A palavra mãe refere-se exclusivamente a uma relação entre mulher branca e seus filhos. Quando a escrava é a mãe, ela é a mãe-preta, ou seja, a ama-de-leite da criança branca" (GIACOMINI, 1988, p. 34).

Ao negar a maternidade das mulheres negras, está sendo inviabilizado o trabalho do cuidado para a criança negra levando-a quase sempre à morte. As mulheres negras escravizadas que tinham filhos eram vendidas ou alugadas como mercadoria-escrava-leiteira ou ama-de-leite. "As crianças seriam de pouca ou nenhuma utilidade aos senhores que alugavam ou compravam escravas para o serviço doméstico, além de representarem um custo suplementar". (GIACOMINI, 1988, p. 54).

A existência de mães-pretas revela mais uma faceta da expropriação da senzala pela casa-grande, cujas consequências inevitáveis foram a negação da maternidade da escrava e a mortandade de seus filhos. Para que a escrava se transformasse em mãe-preta da criança branca, foi-lhe bloqueada a possibilidade de ser mãe de seu filho preto. A proliferação de nhonhôs implicava o abandono e a morte de moleques. (GIACOMINI, 1988, p. 57).

Partimos da compreensão de que o cuidado é uma necessidade ontológica do ser social. A satisfação das necessidades do ser social aparece como produção da vida, tanto da própria, como da alheia, através da conexão materialista entre os indivíduos. Ou seja, para que tenhamos a reprodução, a continuidade e a existência da humanidade é preciso que ocorra a cooperação entre os indivíduos. Nesse processo, existem aqueles que não conseguem ou não podem suprir as suas necessidades ontológicas primárias, o que os coloca como dependentes de um outro. Definimos o cuidado como sendo essa interdependência dos seres humanos, já que ao mesmo tempo há a necessidade do indivíduo para existir e a ação para suprir (PASSOS, 2018).

A distribuição e manutenção desse trabalho está vinculada às determinações de gênero, raça e classe. E ao analisarmos a experiência do ser mulher negra, a funcionalidade do seu lugar de reprodução está coisificada, ou seja, está na zona do não ser (FANON, 2008), não sendo ela mulher e nem mãe, podendo apenas promover o bem-estar e o cuidado da criança branca. Logo, uma das heranças destinadas e deixadas às mulheres negras pelo colonialismo foi o que denominamos de cuidado colonial. Na contemporaneidade ele possui expressões 
que estão vinculadas às suas bases socio-históricas e econômicas que marcaram a existência negra no Brasil, conforme veremos mais adiante.

Essa imagem da mulher negra como 'mãe' vem servindo como um controle de 'raça', gênero e sexualidade. É uma imagem controladora que confina mulheres negras à função de serventes maternais, justificando sua subordinação e exploração econômica. A 'mãe negra' representa a relação ideal de mulheres negras com a branquitude: como amorosa, carinhosa, confiável, obediente e serva dedicada, que é amada pela família branca. (KILOMBA, 2019, p. 142, grifo da autora).

Um segundo ponto diz respeito à sua condição de coisa que está relacionada à particularidade do seu lugar na reprodução social. O que ocorreu foi a penalização da mulher negra escravizada devido às suas funções reprodutivas. Ao negar o ser mulher negra está sendo dito que nós não temos o direito ao nosso corpo, o que permite ao branco apropriar-se da maneira que desejar.

A situação da escrava empregada no trabalho produtivo da plantation esteve necessariamente determinada pela sua condição de coisa, propriedade do senhor. Mas a esta condição, compartilhada com o homem escravo, soma-se a particularidade advinda do fato de ser mulher, isto é, ocupar um papel privilegiado na reprodução biológica. A realização combinada dos potenciais produtivos e reprodutivos da escrava se revelaram incompatíveis sob uma lógica que privilegiou o lucro imediato e conduziu objetivamente ao consumo dos escravos no processo de produção. Compreende-se, pois, que as negras pejadas e as que amamentavam não eram dispensadas da enxada: duras fadigas impediam em algumas o regular desenvolvimento do afeto, em outras minguava a secreção do leite, em quase todas geravam o desmazelo pelo tratamento dos filhos, das doenças e a morte as pobres crianças. (GIACOMINI, 1988, p. 24 grifo da autora).

Para Giacomini (1988) ocorreu um privilegiamento do potencial produtivo em detrimento do reprodutivo da mulher negra. Isto não a isentou de gestar, parir e amamentar os seus filhos. Entretanto, a condição dessa gestação, maternidade e aleitamento sempre foram péssimas, ocasionando uma penalização das mulheres negras por suas funções reprodutivas, levando quase sempre à morte das crianças. Para Magalhães e Giacomini (1980, p. 82), "uma das formas de resistência da escrava à negação de sua maternidade foram os abortos provocados e a morte dos filhos".

A negligência e o descaso dos senhores no tratamento da reprodução escrava parecem ter punido duplamente a portadora do ventre-gerador. Quando grávida, não lhe eram concedidas as condições mínimas necessárias ao desenvolvimento do feto. Quando, a despeito disso, a gravidez vingava, quais seriam as condições que a levariam, muito frequentemente, como sugerem nossos autores, a matar os próprios filhos? (GIACOMINI, 1988, p. 26).

Um terceiro e último ponto, diz respeito a constituição de uma família que é "algo inacessível aqueles que não possuem nem a si próprios", ou seja, "livre para decidir sobre o conjunto da vida do escravo, os interesses do senhor parecem ter sido incompatíveis com a existência de uma família escrava no Brasil" (GIACOMINI, 1988, p. 29). Para Giacomini (1988), a negação da humanidade das mulheres e homens negros implicou diretamente na construção de suas subjetividades, sendo elas violadas, ignoradas, coisificadas, além das relações entre eles — mulheres e homens, mães e filhos, pais e filhos — serem negadas. "Desta forma, ao incorporar a negra ao ciclo reprodutivo da família branca, a escravidão reafirmava a impossibilidade para os escravos constituírem seu próprio espaço reprodutivo” (MAGALHÃES; GIACOMINI, 1983, p. 81).

\section{Mulheres negras, violência e criminalização das necessidades}

As instituições possuem uma função estratégica importante para a reprodução da dominação, do racismo e da violência, o que significa que são fenômenos estruturais (ALMEIDA, 2018). Para Basaglia (1979, p. 102), as "instituições que deveriam defender o cidadão tornaram-se instituições que reprimem o cidadão. A polícia é uma instituição criada para defender o cidadão no interior do Estado". Tais instituições (como a prisão, a escola, o manicômio) servem para estigmatizar e criminalizar as pessoas, além de estarem na defesa e conservação 
dos interesses do Estado (BASAGLIA, 1979). Contudo, as instituições da violência — conforme denominou Basaglia (1985) - possuem ciências que sustentam e dão base às suas práticas consideradas técnicas. São essas técnicas utilizadas por profissionais lotados nessas instituições que operam a violência e, por consequência, o racismo e a dominação.

De acordo com Eurico (2013, p. 299), "o racismo institucional possui duas dimensões interdependentes e relacionadas: a político-programática, e a das relações interpessoais". A primeira diz respeito às ações que vão impedir a formulação, implementação e avaliação de políticas públicas que combatem o racismo. Por sua vez, a segunda dimensão está relacionada às relações entre os gestores, trabalhadores e usuários, pautadas em atitudes discriminatórias. Para a autora, "toda vez que a instituição não oferece acesso qualificado às pessoas em virtude de sua origem étnico-racial, da cor da sua pele ou cultura, o trabalho fica comprometido. Esse comportamento é resultante do racismo institucional" (EURICO, 2013, p. 300).

Ao compreendermos que as instituições reproduzem as múltiplas violências podemos destacar que possuem um importante e estratégico papel para conter a existência da mulher negra e perpetuar o lugar social que nos foi atribuído. As práticas, ações e saberes que justificam o racismo e a violência compõem esses espaços. Portanto, as instituições que devem proteger os cidadãos cumprem esse papel a partir do momento que atualizam tais práticas direcionadas às mulheres negras, ao negarem a nossa condição de ser mulher, coisificando a existência negra e criminalizando pelas necessidades de sobrevivência.

O corpo, a maternidade, o cuidado, o afeto, o amor e a família tudo isso é negado às mulheres negras por meio da violência que se materializa através dos diversos braços do Estado. Não estamos aqui defendendo o mito do amor materno ou uma certa essencialização do gênero feminino, mas problematizamos o lugar que as mulheres negras são condicionadas a ocuparem - a zona do não ser -, o que leva à desumanização e destina ao cuidado colonial. Em relação à criminalização das necessidades de sobrevivência, podemos identificar pelo menos cinco fenômenos que impactam diretamente no existir mulher negra, na maternidade e na constituição do sofrimento. Vejamos:

- A criminalização do aborto: segundo a Pesquisa Nacional de Aborto de 2016, publicada por Diniz, Medeiros e Madeiro (2017), o aborto é comum entre as mulheres brasileiras. A taxa de realização do aborto é mais alta entre as amarelas, negras (pretas e pardas) e indígenas. Casseres (2018) analisou 42 ações penais que estavam relacionadas ao artigo 124 do Código Penal brasileiro que trata do aborto realizado pela pessoa ou por consentimento de outro. A autora dividiu sua análise em dois grupos: o primeiro era composto por 20 mulheres que realizaram aborto sem assistência, sendo que o perfil racial dessas jovens era de $60 \%$ de negras, com idade entre 18 e 36 anos na data dos fatos, e o segundo concentrou as 22 mulheres processadas por terem sido atendidas em clínicas clandestinas. Destaca-se que apenas em uma das clínicas clandestinas não havia profissional com formação médica. O perfil compreendia mulheres de 19 a 40 anos, sendo $53 \%$ brancas, $75 \%$ cursaram o ensino médio e a proporção de atendidas pela Defensoria Pública foi menor que o primeiro grupo. Para Casseres (2018, p. 81), a renda e a raça "são decisivos no enfrentamento do estigma imposto pela incriminação do aborto e gestão dos recursos disponíveis para que os dois grupos de mulheres submetidas à ilegalidade penal possam proteger suas próprias vidas".

- Violência obstétrica: A Pesquisa nascer no Brasil, realizada pela Fiocruz, identificou que as mulheres negras representam 65,9\% daquelas que sofrem violência obstétrica (LANSKY et al., 2014), sendo que do público total atendido nos serviços do Sistema Único de Saúde 67\% são negros (BRASIL, 2017). Segundo Assis (2018, p. 560), no município do Rio de Janeiro os índices de óbitos maternos apresentam uma das mais altas taxas, "superando a média do país, que gira em torno de sessenta mortes por 100 mil nascidos vivos". Em relação ao perfil das mulheres, no período de 2000 a 2013, dados disponibilizados pelo Sistema de Informações sobre Mortalidade Materna (SIM), indicam que "o município do Rio de Janeiro registrou 273 mortes de mulheres brancas, enquanto o mesmo indicador para mulheres negras somou um total de 485 mortes. Ou seja, as mulheres negras morrem em média $56 \%$ a mais que as brancas durante o período gravídico puerperal" (ASSIS, 2018, p. 56).

- Retirada compulsória dos bebês: A Pesquisa Nacional sobre o uso de crack, de 2014, realizada pela Fundação Oswaldo Cruz, localizou que a maioria das mulheres que fazem uso prejudicial de crack não são brancas e representam 78,56\% das identificadas, tendo entre 18 a 24 anos de idade. Além disso, 
$51,61 \%$ delas informaram que 30 dias antes da entrevista se encontravam em situação de rua (BASTOS; BERTONI, 2014). Em relação à saúde reprodutiva dessas mulheres, conforme apresenta a Vaz et al. (2014, p. 16), na cidade do Rio de Janeiro, de 53 mulheres identificadas, entre janeiro e junho de 2013, como usuárias de crack e em situação de rua e que foram atendidas em maternidades, "apenas 14 saíram do hospital com seus filhos. As demais 39 foram afastadas deles, encaminhadas para abrigos (19), outros familiares (10), adoção (4), dentre outros".

- Suicídio da juventude negra: O Ministério da Saúde publicou em 2018, o Relatório Óbitos por suicídio entre adolescentes e jovens negros 2012-2016, que mostra o crescente índice de suicídio no país chegando a ser a quarta causa de morte nesses grupos etários. No caso dos adolescentes negros, "a primeira causa de morte são os homicídios, seguida de acidentes (incluindo acidentes de trânsito), neoplasias malignas e o suicídio" (BRASIL, 2018, p. 5). Entre 2012 a 2016, a proporção de suicídios entre negros aumentou subindo de 53,3\% em 2012 para 55,4\%, quando comparado às demais raças/ etnias. Em síntese a proporção, no ano de 2016, foi de 39,0\% de brancos, 49,3\% de pardos, $6,1 \%$ pretos e 2,9\% de indígenas. No Estado do Rio de Janeiro a proporção é de 2,9\% para cada 100 mil óbitos (BRASIL, 2018).

- Assassinato de filhos, companheiros e familiares: De acordo com os dados publicados pelo Atlas da Violência de 2019, em uma década (2007 a 2017), a taxa de homicídios em relação aos negros (pretos e pardos) cresceu 33,1\%, enquanto a de não negros obteve um pequeno aumento de 3,3\%, o que também gerou uma continuidade no "processo de aprofundamento da desigualdade racial nos indicadores de violência letal no Brasil, já apontado em outras edições" (p. 49). Já, no Estado do Rio de Janeiro, 5964 pessoas sofreram letalidade violenta ${ }^{2}$, sendo 34,6\% para cada 100 mil habitantes. Na capital metropolitana, em 2019, foram 1.909 mortes por letalidade violenta, sendo $28,7 \%$ por 100 mil habitantes (RIO DE JANEIRO, 2020).

Portanto, "nós negros estamos na lata de lixo da sociedade brasileira, pois assim determina a lógica da dominação" (GONZALES, 1984, p. 225). Os impactos gerados pelo fenômeno do racismo, do colonialismo, do sexismo, do patriarcado e do elitismo foram/são violentos para as mulheres negras, produzindo um sofrimento colonial. É esse sofrimento que assumiu a composição do existir mulher negra, tendo o genocídio como tática atualizada de expropriação da maternidade negra e que reafirma a mãe preta como "folclore dos brancos e miséria das negras" (MAGALHÃES; GIACOMINI, 1983, p. 82).

\section{Considerações Finais}

O presente artigo procurou retratar como foi constituído o existir mulher negra na sociedade brasileira dando destaque à negação da maternidade, a sua coisificação e a criminalização das necessidades da sobrevivência. A partir do diálogo entre Basaglia e Fanon compreendemos que o sofrimento do ser negro é oriundo do processo de colonização que criou a racialização dos povos, dos corpos e das culturas. Nesse caminho, a composição do existir mulher negra se deu na zona do não ser, sendo-lhe negadas as características destinadas ao gênero feminino, tendo como traço marcante o sofrimento de sobrevivência.

A partir de uma análise teórica que dialoga com situações vivenciadas por mulheres e publicizadas por reportagens e dados estatísticos, procurou-se trabalhar por meio da escrita interseccionalizada, que não se descola da realidade e analisa os fenômenos do cotidiano por meio do imbricamento entre gênero, raça e classe. Assim, objetivamos desvelar acerca do sofrimento que é destinado às mulheres negras e que está vinculado à violência e ao racismo estrutural, tendo no genocídio da população negra a sua base.

Ao serem localizadas na zona do não ser, as mulheres negras são desumanizadas, sendo destinado o cuidado colonial, o que significa que não se pode prover a subsistência e a existência, ou seja, criminaliza-se as necessidades e extermina-se os frutos dessa maternidade. Como consequência, ocorre a patologização e a medicalização do ser mulher negra como fenômeno crescente da sociedade contemporânea. Dessa forma, reatualiza-se o manicômio, promovendo no existir mulher negra a dor, o adoecimento e a morte como único caminho. 


\section{Referências}

ALMEIDA, S. O que é racismo estrutural? Belo Horizonte: Letramento, 2018.

ASSIS, J. Interseccionalidade, racismo institucional e direitos humanos: compreensões à violência obstétrica. Revista Serviço Social e Sociedade, São Paulo, n. 133, p. 547-565, set./dez. 2018.

BASAGLIA, G. A psiquiatria alternativa: contra o pessimismo da razão, o otimismo da prática. São Paulo: Ed. Brasil Debates, 1979. BASTOS, F. I.; BERTONI, N. (org.). Pesquisa Nacional sobre o uso de crack: quem são os usuários de crack e/ou similares do Brasil? Quantos são nas capitais brasileiras? Rio de Janeiro: ICICT; FIOCRUZ, 2014.

BELL HOOKS. E eu não sou uma mulher: Mulheres negras e feminismo. Rio de Janeiro: Editora Rosa dos Tempos, 2019.

BRASIL. Ministério da Saúde. Óbitos por suicídio entre adolescentes e jovens negros 2012-2016. Brasília: Universidade Federal de Brasília, 2018.

BRASIL. Ministério da Saúde. Política Nacional de Saúde Integral da População Negra: uma política do SUS. 3. ed. Brasília, DF, 2017. BRISO, C. B. O adeus de Joselita, mãe de menino morto em Costa Barros. O Globo, 9 jul. 2016; atualizado em 24 jan. 2019. Disponível em: https://oglobo.globo.com/rio/o-adeus-de-joselita-mae-de-menino-morto-em-costa-barros-19680236. Acesso em: 22 fev. 2020.

CARNEIRO, S. Gênero, raça e ascensão social. Revista Estudos Feministas, Florianópolis, v. 3, n. 2, 1995.

CARVAlHO, M. A. 75\% das vítimas de homicídio no País são negras, aponta Atlas da Violência. Estadão, São Paulo, 5 jun. 2019. Disponível em: https://brasil.estadao.com.br/noticias/geral,75-das-vitimas-de-homicidio-no-pais-sao-negras-aponta-atlas-daviolencia,70002856665. Acesso em: 10 set. 2019.

CASSERES, L. M. M. D. Racismo estrutural e a criminalização do aborto no Brasil. Revista SUR 28, v. 15, n. 28, p. 77-85, 2018.

DINIZ, D.; MEDEIROS, M.; MADEIRO, A. Pesquisa Nacional de Aborto 2016. Revista Ciência e Saúde Coletiva, v. 22, n. 2, p. 653-660, 2016.

EURICO, M. A percepção do assistente social acerca do racismo institucional. Revista Serviço Social e Sociedade, São Paulo, n. 114, p. 290-310, abr./jun. 2013.

FANON, F. Condenados da Terra. Juiz de Fora: Ed. UFJF, 2015.

FANON, F. Em defesa da Revolução Africana. Portugal: Editora Livraria Sá da Costa, 1980.

FANON, F. Peles negras, máscaras brancas. Salvador: Ed. UFBA, 2008.

GIACOMINI, S. M. Mulher e Escrava: uma introdução histórica ao estudo da mulher negra no Brasil. Petrópolis: Vozes, 1988.

GONZALEZ, L. Racismo e Sexismo na Cultura Brasileira. Revista Ciências Sociais Hoje, ANPOCS, p. 223-244, 1984.

IRACI, N.; WERNECK, J. A situação dos direitos humanos das mulheres negras no Brasil: violências e violações. Portal Geledés, 30 set. 2016. Disponível em: https://www.geledes.org.br/situacao-dos-direitos-humanos-das-mulheres-negras-no-brasil-violenciase-violacoes/. Acesso em: 10 set. 2019.

KILOMBA, G. Memórias da Plantação: episódios de racismo cotidiano. Rio de Janeiro: Editora Coboró, 2019.

LANSKY, S. et al. Pesquisa nascer no Brasil: perfil da mortalidade neonatal e avaliação da assistência à gestante e ao recém-nascido. Cad. Saúde Pública, Rio de Janeiro, v. 30, supl. 1, 2014.

LEÃO, T. M.; IANNI, A. M. Z.; GOTO, C. S. Sofrimento psíquico e a universidade em tempos de crise estrutural. Revista Em Pauta, Rio de Janeiro, n. 44, v. 17, p. 50-64, 2019.

MAGALHÃES, E. K. C.; GIACOMINI, S. M. A escrava ama-de-leite: anjo ou demônio? In: BARROSO, C.; COSTA, A. O. (org.). Mulher, Mulheres. São Paulo: Cortez; Fundação Carlos Chagas, 1983.

PASSOS, R.G. Trabalho, Gênero e Saúde Mental: contribuições para a profissionalização do cuidado feminino. São Paulo: Cortez, 2018. QUIJANO, A. A colonialidade do poder: eurocentrismo e ciências sociais. Buenos Aires: CLACSO, 2005.

RIO DE JANEIRO. Instituto de Segurança Pública. Séries históricas anuais de taxa de letalidade violenta do Estado do Rio de Janeiro e Grandes Regiões, Rio de Janeiro, jan. 2020.

VAZ, A. L. et al. Oficinas discutem rede de proteção à mãe e seu bebê. Revista Práxis, Volta Redonda, n. 76, mar./abr. 2014.

\section{Notas}

1 Referência à expressão elaborada por Lélia Gonzalez (1984).

2 Letalidade violenta corresponde ao somatório dos seguintes títulos: homicídio doloso, roubo seguido de morte (latrocínio), lesão corporal seguida de morte e morte decorrente de intervenção de agente do Estado. 


\section{Rachel Gouveia Passos}

rachel.gouveia@gmail.com

Doutorado em Serviço Social pela Pontifícia Universidade Católica de São Paulo (PUC/SP)

Professora Adjunta da Escola de Serviço Social da Universidade Federal do Rio de Janeiro (ESS/UFRJ)

Colaboradora do Programa de Pós-Graduação em Política Social da Universidade Federal Fluminense (PPGPS/UFF)

\section{UFRJ}

Avenida Pasteur 250, fundos, sala 36B. Urca.

Rio de Janeiro - RJ - Brasil.

CEP: $22.290-240$

\section{Agradecimentos}

Não se aplica.

Agência financiadora

Não se aplica.

Contribuições das autoras

A autora organizou e elaborou o artigo. O mesmo é fruto das reflexões oriundas da pesquisa Mulheres negras, sofrimento e cuidado colonial vinculada ao Projeto de Pesquisa e Extensão Aprovação por Comitê de Ética e consentimento para participação

Não se aplica.

Consentimento para publicação

Consentimento da autora.

Conflito de interesses

Não há conflito de interesses.

Luta Antimanicomial e Feminismos. 